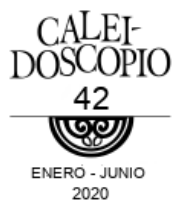

\title{
El fanzine como fenómeno cultural en la Ciudad de México
}

The fanzine genre as a cultural phenomenon in Mexico City

JUAN ALBERTO MARTÍN DEL CAMPO JIMÉNEZ Universidad Autónoma de Aguascalientes, México

\section{RESUMEN}

El fanzine en la Ciudad de México cobró mucha fuerza en los años ochentas del siglo XX. Era considerado un producto subversivo, abyecto y subterráneo. Actualmente forma parte de la cultura visual como un escaparate donde muchos jóvenes encuentran maneras de promover su trabajo como creadores, les permite identificarse, crear espacios de afinidad y convivencia. Ya no se trata de una manifestación exclusivamente contracultural sino una herramienta experimental y una plataforma creativa para la ilustración y las artes visuales.

Palabras clave: fanzine; contracultura; ilustración.

\section{ABSTRACT}

The zines in Mexico City gained great strength in the eighties of the Twentieth Century. They were considered as subversive products from the underground. Currently part of the visual culture as a showcase where many young people find ways to promote their creations, allows them to identify, generate spaces of affinity and coexis- 
tence. It is no longer an exclusively manifestation of counterculture but an experimental tool and a creative platform for illustration and visual arts.

Keywords: fanzine; counter culture; illustration.

El fanzine es un fenómeno cultural relacionado con el ámbito editorial independiente y autogestivo. El significado de este concepto proviene del inglés Fan Magazine (revista de aficionados). De acuerdo a Chris Atton y su libro Alternative media (2002) se trata de una revista impresa de un tiraje muy limitado y reproducida a partir de medios diversos como el mimeógrafo, la fotocopiadora, la risografía, la serigrafía, el grabado y algunas impresoras (Atton, 2002).

Los formatos utilizados, materiales y formas de armado varían de acuerdo al objetivo de su producción. El contenido puede tocar distintos temas, incluso puede tratarse de una historieta o un objeto creativo experimental donde se presentan ilustraciones generadas en cualquier técnica posible. Su forma de difusión y distribución es personal e independiente.

En la actualidad muchos fanzines se difunden a través de internet, usualmente desde Facebook y Tumblr. También existen los $e$-zines, que son publicados de manera digital en sitios como Issuu. Desde la perspectiva de Atton (2002), los medios electrónicos han favorecido la interacción entre los productores, colectivos y públicos, debido a que gran parte del uso de internet se ha cobijado bajo ideales cercanos o totalmente acordes con los principios del fanzine impreso, que involucran la promoción de prácticas de 
comunicación autogestivas, rápidas e independientes, de difusión libre, a bajo costo o gratuitas y sin intermediarios (Atton, 2002).

En ámbitos de investigación el fanzine es un fenómeno poco explorado, solo es mencionado como práctica cultural de determinados grupos juveniles o como medio de difusión musical, sobre todo del rock, en ese sentido y por su naturaleza subterránea es difícil de rastrear y documentar.

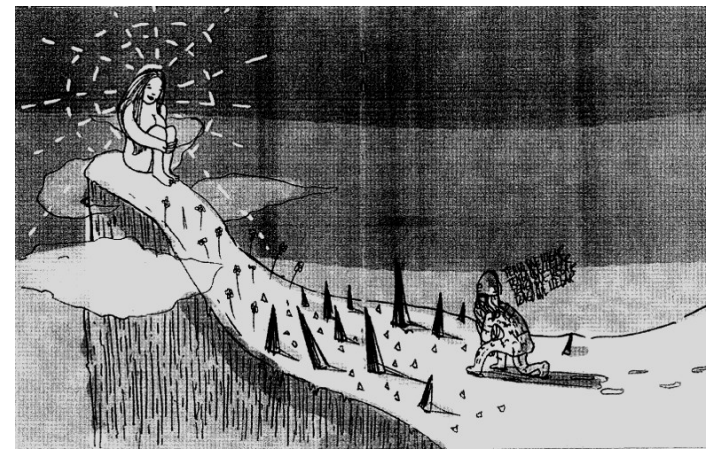

Figura 1. Infierno I, 2014, Dr. Intransferible.

La antropóloga Aida Analco Martínez (2011), relata que el Fan Kingdom se refiere a una generación norteamericana de aficionados que comenzaron a publicar sus propias revistas impresas en mimeógrafo a partir del culto a historietas de ciencia ficción, principalmente Amazing Stories de Hugo Gernsback en los años veinte del siglo XX. Afirma también que la palabra fue acuñada por Louis Russell Chauvenet en los años treinta junto con el término Prozine (Profesional science fiction magazine).

The Comet (posteriormente llamado Cosmology), publicado en 1926 por Raymond A. Palmer y Walter Dennis es 
considerado el primer fanzine, que inició como un sistema de correspondencia entre los aficionados, para después convertirse en una publicación artesanal que narraba historias muy parecidas a las que se presentaban en las novelas de ciencia ficción de la época. Este fue el detonante de la aparición de fanzines similares que fueron publicados posteriormente (Analco, 2011).

No es hasta los años sesentas del siglo veinte que este fenómeno comienza a tener una relación estrecha con la contracultura juvenil que se desarrollaría mediante el periodismo musical, la literatura alternativa y la historieta underground, cuestiones que serían detonantes del impacto del fanzine en la cultura contemporánea.

Aunque podemos afirmar que el fanzine en la actualidad ya no se manifiesta estrictamente como un producto cultural subversivo, rebelde y contestatario, su historia tuvo un período importante donde fue adoptado con énfasis por contraculturas, subculturas y culturas alternativas relativas al rock, al punk y a la literatura a partir de los años sesenta y setenta del siglo XX.

Esas dos décadas representaron una época de efervescencia para los movimientos juveniles donde hubo una gran exploración gráfica en el ámbito del cartel, las portadas de discos y publicaciones alternativas. Con respecto a este contexto, Analco (2011) afirma: "Cualquiera con un medio de impresión y una opinión podía darse el derecho a la palabra, a gritar sus inconformidades y críticas desde unas hojas de papel. Muchos lo hicieron. La historia del fanzine moderno había comenzado" (p. 42).

\section{El FANZINE EN LA CIUDAD DE MÉXICO}

En México el Tianguis Cultural del Chopo a partir de los años ochenta del siglo XX ha representado un espacio 
importante para la distribución y difusión del fanzine. Jorge Pantoja, miembro fundador, realizó una recopilación de crónicas llamada Cuando el Chopo despertó, el dinosaurio ya no estaba ahi (2007), donde se relata la importancia de este tianguis para las culturas alternativas y juveniles de México.

Uno de los autores más importantes que se incluye en esta compilación es Carlos Monsiváis (Citado en Pantoja, 2007), cronista por excelencia de la cultura popular en México, quien a través del texto nos introduce contextualmente al tianguis:

El tianguis del Chopo es un templo de la contracultura mexicana. Apareció allá por 1979 o 1980 a las afueras del Museo del Chopo, como resultado de la tendencia natural al intercambio, el famoso potlach de la antropología. Un chavo se lanza a vender discos y la siguiente semana le secundan, y otros nomás acuden al canje y pronto, con la celeridad de la economía subterránea, se establece el mercado, y florece el capitalismo del siglo XVIII, se determinan más o menos los precios módicos, abundan los casettes, los discos pirata, las artesanías post-hippies, los souvenirs de groupies (Monsiváis en Pantoja, 2007, p. 23).

José Agustín (1996) también narra la importancia del Tianguis del Chopo, que hasta la fecha sigue siendo un espacio común para el rock, el punk y la cultura alternativa, donde también circula el fanzine:

Abundaban los discos, cintas y videos pirata, y alli estaba toda la ropa, la indumentaria y parafernalia para punks, postjipis y machines de todo tipo. También abundaban las revistas y fanzines rocanroleros de todas partes, así es que en unos cuantos años el Chopo se convirtió en la capital de la contracultura en México (Ramírez, 1996, p. 105).

Como parte de la documentación de esta historia podemos hablar del libro Fanzinología mexicana 1985 - 2015

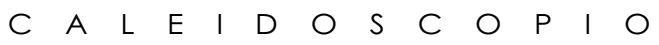


(2015) editado por Enrique Arriaga Celis e Inés Estrada a través del Museo Universitario del Chopo, se trata de una recopilación de imágenes de fanzines publicados durante los últimos treinta años en nuestro país; nació de un proyecto llamado "Fanzinoteca del Museo Universitario del Chopo", iniciativa de los autores que tiene como finalidad producir, coleccionar y difundir publicaciones autoeditadas; Arriaga y Estrada (2015), toman en cuenta las implicaciones de llevar al fanzine al espacio museístico a través de esta Fanzinoteca:

Hasta cierto punto, resulta paradójico que un museo implemente un programa para exhibir y coleccionar impresos cuyo ímpetu de factura y consumo es inmediato. Sin embargo hay que reconsiderar que debido a la precariedad de estas publicaciones (tirajes cortos, escasa circulación, ser dispensables) son más susceptibles a desaparecer y por lo tanto resulta necesario (aunque problemático) darse a la tarea de rescatarlos y ofrecer nuevas lecturas sobre los modos de producción y consumo de esos materiales [...] También representa una contradicción intrínseca el exhibir y por lo tanto legitimar cierto tipo de producción cultural que desde su origen pretende resistir los espacios de autoridad y normalización. A pesar de las problemáticas que pueden surgir de introducir a un museo productos culturales, este tipo de cooptación ha venido sucediendo desde el momento en que estas prácticas emergen: parecen ser desplazamientos inherentes a la relación entre cultura y contracultura (p. 151-52).

Estas acciones muestran el creciente interés de investigación por el fenómeno, especialmente por el registro de imágenes y pese a que la publicación de este libro sirve primordialmente como catálogo, el ejercicio de recopilar y generar espacios para el resguardo y exhibición de fanzines mexicanos representa en sí mismo una gran aportación para el tema. 


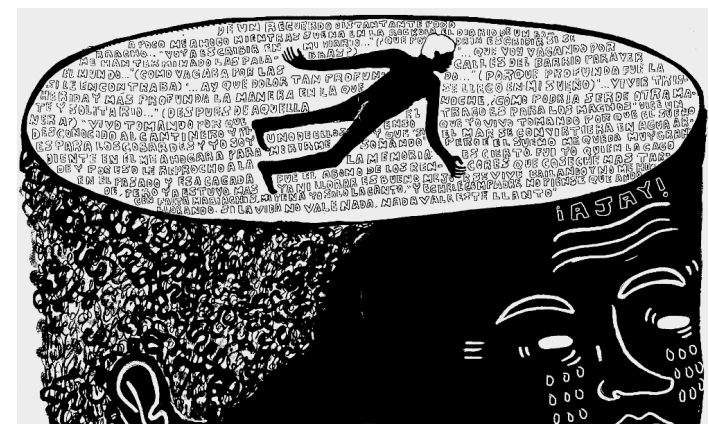

Figura 2. Lxvxz zin pellejo. Slam poetry, 2015, Patricia Ávila y Axcel Zárate.

\section{ActuAlidAD DEL FANZINE EN LA CIUDAD DE MÉXICO}

La Fanzinoteca del Museo del Chopo y el libro Fanzinología Mexicana 1985-2015, son proyectos que juegan un papel importante para la comprensión del fenómeno del fanzine en la Ciudad de México ya que a partir de ellos se ha impulsado el desarrollo de lo que sucede actualmente en los festivales y eventos de gráfica alternativa. Es el propio Arriaga Celis (Arriaga y Estrada, 2015) quien narra parte de la historia de los fanzines y su vínculo con el Museo del Chopo:

La decisión de abrir un espacio para la conservación, difusión y producción de fanzines en un museo auspiciado por la UNAM, cuyo principal público son los jóvenes y estudiantes, es consecuente con la historia del museo. Durante su "época de oro" (las décadas de los ochenta y noventa), el Museo del Chopo fue una institución que fomentó el imaginario vinculado con la cultura juvenil, las subculturas, el rock, el arte experimental y las nuevas convenciones artísticas, así como lo que en aquellos años se relacionaba con la difusa esfera de "lo alternativo". Los primeros fanzines punk comenzaron a circular en "El Chopo" (tanto en el museo como en el tianguis), donde también se reunían distintos colectivos y se hacían las tocadas de este género musical, entre otros. Prueba de ello, es que en varias de las páginas de estas 
publicaciones se puede encontrar información sobre eventos que se llevaron a cabo en el museo, hace más de tres décadas (p. 145).

Para comprender la actualidad del fanzine es necesario tomar en cuenta su desarrollo en los años noventa, ya que es en esa década donde este fenómeno se expande ampliamente desde el periodismo musical. En esa época comenzó a darse con mucha fuerza la socialización entre diversos grupos juveniles, además hubo una gran cantidad de foros y encuentros de productores y colectivos que propiciaron el intercambio de ideas y fomentaron un espíritu de colectividad creciente con el paso de los años, todo ello debido a la interculturalidad que se dio con las relaciones entre grupos juveniles con gustos musicales diversos y a las nuevas posibilidades de comunicación que dio el internet. Analco (2011) explica de manera clara cómo se desplegó el fenómeno en esa época:

Con la llegada de la década de los noventa, la práctica de realizar fanzines se difunde por diferentes partes del país y distintos grupos juveniles la retoman para, desde sus páginas, dar rienda suelta a la expresión de sus ideas, imaginarios, sueños y gustos. Los realizadores de fanzine de esta década potenciarán la experiencia de los fanzineros de la época anterior, el intercambio postal será sustituido por la comunicación virtual a través de Internet, se fortalece la creación de foros y encuentros entre jóvenes de diferentes estados de la república y de otros países, con lo que el intercambio de experiencias cara a cara también incidirán en la proliferación de fanzines. Los fanzines se diversifican y no sólo son un órgano de expresión para los grupos punks, sino que emergen otros grupos juveniles con distintos intereses, la experiencia punk había sembrado la semilla y ahora los fanzines son retomados como foro de expresión para nuevos sujetos juveniles como los skinheads, skaseros, reggaeseros, straight edge, estudiantes, entre otros, que continuarán con la elaboración de fanzines durante esta década hasta llegar a los inicios del siglo XXI (p. 82). 
Ya entrada la primera década del año 2000, Internet y la banda ancha no solo supusieron para los colectivos y productores de fanzine un medio de comunicación sino también una plataforma para mostrar su trabajo gráfico. Muchos fanzines de periodismo musical, literatura y otros temas desparecieron del panorama del formato impreso y de las fotocopias para alojarse en blogs, esos sitios web de carácter personal que alojan contenidos estructurados cronológicamente, se actualizan con regularidad y tratan algún tema en concreto. Años más adelante en la Ciudad de México y en otros lugares de la república cobró gran relevancia el fanzine de ilustración y narrativa gráfica. Muchos artistas visuales, diseñadores e ilustradores han recurrido a plataformas como Tumblr, Facebook y Behance entre otras, para mostrar su trabajo de producción visual. Es a partir de la segunda década del siglo XXI cuando se despierta el interés de muchos jóvenes por el fanzine como medio creativo. Surgen "fanzinoferias", nuevos productores y colectivos de fanzine. Una serie de acontecimientos que fomentaron este interés fueron las actividades que antecedieron a la creación de la Fanzinoteca del Museo del Chopo, que de acuerdo a Arriaga Celis incluyeron algunos ciclos, eventos y muestras:

El primer ciclo del programa se llevó a cabo de abril 2013 a julio 2014, periodo en el que se realizaron seis muestras, acompañadas cada una por una serie de eventos. Gracias a los préstamos de los invitados y las donaciones, se obtuvo el material para conformarse este acervo público de impresos autoeditados. (Arriaga y Estrada, 2015, p.143)

Los festivales de fanzine y de gráfica alternativa han generado un gran ímpetu e interés entre los jóvenes, ya que a partir de ellos han surgido una gran cantidad de propuestas estéticas, muchas de ellas no están enfocadas 
al fanzine, ya que destacan también los stickers, posters, playeras impresas en serigrafía, libretas artesanales y demás productos. Aunque actualmente existen una gran cantidad de festivales que replican a su manera algunos eventos de publicaciones independientes llevados a cabo en países europeos como Francia, España, Italia e Inglaterra, fue a partir del año 2012 que se generó este formato en México para la exposición y venta de fanzines y otros productos basados en la creación gráfica, tal como lo explica Arriaga Celis:

Entre 2012 y 2014 se organizaron un buen número de pequeños festivales - uno de los principales fue el Zin Amigos - que progresivamente ha ido creciendo en cuanto a sus públicos y proliferado por diversos circuitos de la ciudad. En estos espacios presentan e intercambian sus trabajos artistas, ilustradores, diseñadores, aficionados y dibujantes, entre otros, que retoman modos de producción, circulación y tratamientos relacionados con la ética del "hazlo tú mismo". Este notorio auge de publicaciones autoeditadas por parte de diversos productores fue una razón de peso para voltear a ver lo que estaba sucediendo y, de alguna forma, propulsar el interés desde el Museo Universitario del Chopo, plataforma institucional que tiempo atrás fomentó el desarrollo de esta forma de producción cultural en la Ciudad de México (Arriaga y Estrada, 2015, p.144).

Al crecer el proyecto de la Fanzinoteca del Museo del Chopo, muchos productores y colectivos de fanzine se interesaron en formar parte de ella a través de sus publicaciones, este ha sido uno de los detonantes más importantes para el surgimiento de proyectos similares: nuevos festivales de fanzine, nuevos colectivos y talleres editoriales de fanzine, Arriaga Celis da cuenta de ello:

El proyecto fue creciendo gradualmente y en el transcurso de cada muestra se fue estableciendo (para bien o para mal). Esto se puede constatar con la museografía, que conforme avanzaban las 
ediciones, se tornó cada vez más elaborada. El que las muestras hayan captado la atención de algunos medios, que algunos fanzineros se interesaban por formar parte de la colección y que el proyecto diera a conocer los fanzines a nuevos públicos, fueron indicios de que la Fanzinoteca se encontraba en un aparente proceso de consolidación: por un lado, en diálogo con los protagonistas y circuitos de este fenómeno; y por otro al interior del museo, en sintonía con su plan de trabajo (Arriaga y Estrada, 2015, p. 146).

Por su parte Inés Estrada (2015), ilustradora, productora y recopiladora de fanzines da su punto de vista sobre el estado actual de este fenómeno cultural, que ya no esta relacionado directamente con subculturas o contraculturas contestatarias, más bien ha ido transformándose y fluctuando entre las múltiples ofertas de productos estéticos autogestivos:

Esta recopilación pretende conformar una referencia para contextualizar las ramificaciones del movimiento fanzinero en México a través de las últimas décadas, destacando las expresiones gráficas y de narrativa visual únicas de estas publicaciones. Hoy en día el fanzine se ha sido reapropiado fuera de las subculturas que lo originaron, pero nada nace de un vacío, y menos en el mundo de los fanzines, donde todo se fotocopia y se reproduce (Arriaga y Estrada, 2015, p. 161).

La efervescencia del fanzine en los últimos años ha sido producto de la interculturalidad, de las experiencias compartidas y del entusiasmo por la creación estéticovisual que está tomando cada vez mayor fuerza entre distintos sectores juveniles de la Ciudad de México y muchos lugares del país, ya no desde un sentido subversivo sino con una actitud relajada, en donde las propuestas de dibujo e ilustración toman mucha fuerza. Alex Aceves Bernal (2015) en su ensayo "Zin-Generación" 
explica de manera general cómo ha cambiado el fanzine y la gráfica alternativa en México a partir de los festivales:

\begin{abstract}
En la actualidad, en México estamos viviendo un boom en la producción de fanzines y de festivales dedicados a la difusión, intercambio y venta de los mismos. El 31 de marzo del año 2012, el festival Zin Amigos inició una oleada de proyectos que en ese momento era insospechada. El festival tuvo tres ediciones más, una en Cholula, y las demás en la galería Néter del Distrito Federal, todas realizadas durante 2012. Durante los años siguientes, eventos similares comenzaron a suceder en diferentes espacios culturales independientes, y para el año 2015, la cantidad de festivales dedicados a la venta e intercambio de fanzines fue tan alta que en ocasiones se empalmaban sus fechas: Fanzinorama (que en la actualidad lleva realizadas 8 ediciones), Lobo Zin Pellejo (3 ediciones), Zin Reino, Zin Zezoz, Matazanos (4 ediciones), Zin Amibas (en Cuernavaca), Zin Futuro (en Guadalajara, 2 ediciones), Rrréplica, Zine Zensura, Zine Fest, entre muchos otros. En tan sólo cuatro años, los fanzines en México pasaron de ser un fenómeno relegado a las periferias de la producción cultural, a ser objeto de revisiones históricas en el Museo del Chopo (a través de la Fanzinoteca), y contar con espacios de exposición y venta en diversos museos, ferias del libro y bazares (Aceves, 2015).
\end{abstract}

Son estos eventos mencionados por Alex Aceves Bernal los que en estos últimos años han puesto a la vista de un público cada vez más amplio el fenómeno de la autoedición, algunos de esos festivales desaparecieron, otros han continuado y algunos más se siguen sumando. Todos ellos son llevados a cabo en galerías independientes, casas, bares y foros culturales; son organizados y gestionados por los propios colectivos y productores que utilizan plataformas digitales como Facebook y Tumblr para difundirlos, cabe mencionar que algunos de ellos han mostrado su trabajo en ferias de libro y en distintos museos como el Museo de Arte Carrillo Gil, lugares que 
dan cabida y apertura a editoriales independientes, dentro de las cuales el fanzine es tomado en cuenta.

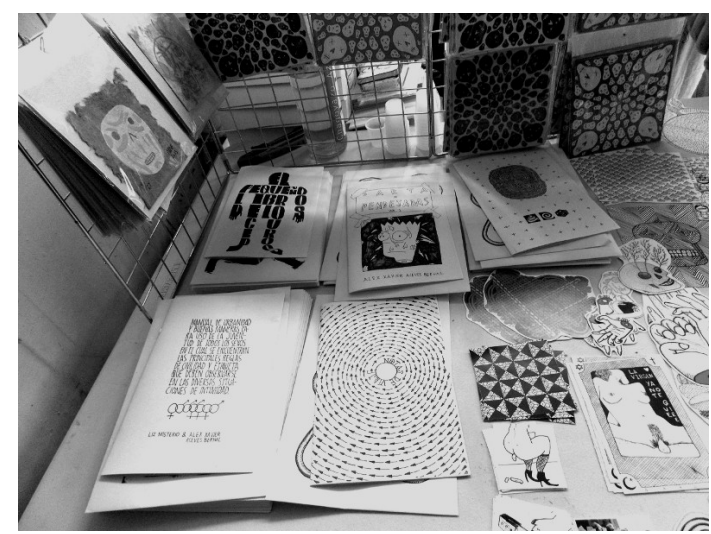

Figura 3. Martín del Campo, J., 2015, Festival de fanzine Zinzezoz [fotografía].

Si pudiéramos hablar de una fenomenología del fanzine para encontrar los puntos comunes entre lo que se produjo dentro del fan kingdom en los años veintes del siglo pasado hasta las auto-publicaciones actuales, seguramente uno de los conceptos imperantes será el de autogestión. Utilizado en múltiples contextos, sobre todo en ámbitos de economía y política ha sido resignificado para entenderlo no solo como un planteamiento de auto-organización anarquista, sino también como una forma de llevar a cabo actividades cotidianas.

La esencia de identidad de clase o las maneras subversivas de actuar ya no son un imperativo en nuestra época, ya sea por la relativización de las ideologías contestatarias, la democratización de las opiniones o por la manera en que se han atenuado o cooptado muchos movimientos civiles. El capitalismo y las formas de vida en la sociedad contemporánea de 
consumo dictaminan y ordenan en gran manera las relaciones humanas y todo lo que de ellas se produce, con esto queda claro que los productos culturales son asimilados como mercancías. Este paradigma utilitarista y mercantilista genera grandes diferencias sociales que impiden la existencia de muchas formas de autonomía comunitaria, es por eso que el fanzine navega y oscila entre campos comerciales y culturales, donde el auto-gestionarse recursos, materiales, formas de producción y difusión resulta la manera más inmediata de hacerse visible en el panorama creativo de la narrativa gráfica y la ilustración en la Ciudad de México.

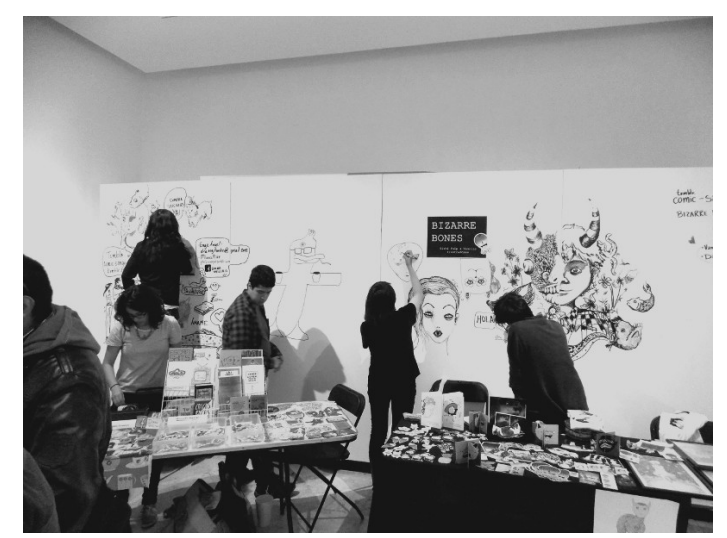

Figura 4. Martín del Campo, J., 2015, Festival de fanzine Fanzinorama |fotografía).

En gran manera el fanzine ilustrado es diferente a mucho de lo que se muestra en historietas, álbumes ilustrados u otros productos culturales semejantes; se encuentra lleno de imágenes que en muchos ámbitos se considerarían vulgares, raras, callejeras, ilegibles o incoherentes; estas características son propias de un quehacer autogestivo. Los productores y 
colectivos se auto-publican no solo para hacerse de una plataforma cultural inmediata sino también para expresar ideas que en otros espacios serían modificadas o censuradas, esto trae consigo innovaciones creativas que no son fáciles de encontrar en otro tipo de publicaciones.

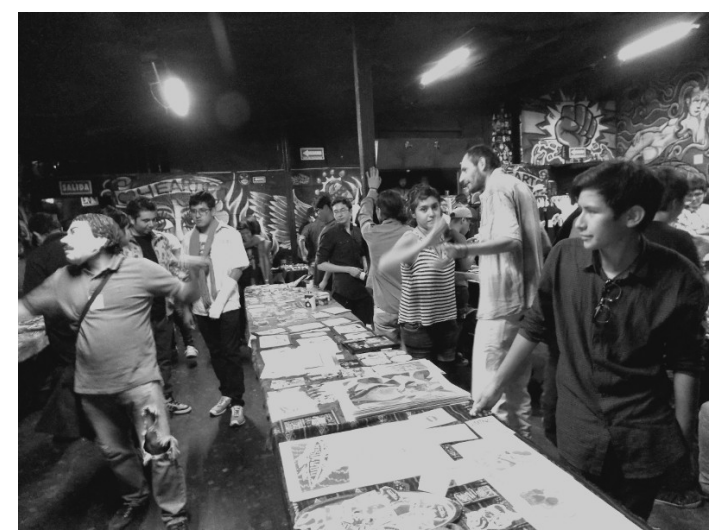

Figura 5. Martín del Campo, J., 2015, Festival de fanzine Fanzinorama [fotografía].

Por otro lado, en la actualidad se han desdibujado las diferencias entre lo que se considera un producto comercial y un producto cultural "puro", las publicaciones independientes son prueba de ello ya que para los creadores de fanzine no existen limitaciones por participar en proyectos de diversa índole, explorar nuevos medios o técnicas, exponer en galerías o mercantilizar su trabajo; todo eso forma parte de subjetivaciones contemporáneas, donde los individuos actúan conforme al orden del consumo; nuestras formas de vivir se rigen por ciertos ordenes y procesos políticos que se modifican constantemente pero que giran en torno a los movimientos y fluctuaciones del capital. Las libertades de elección se sujetan a la masificación y a nuestro estatuto como usuarios de bienes. El 
auto-gestionarse y auto-producirse para tener "visibilidad social" es parte de nuestra vida cotidiana. El fanzine contemporáneo lo hace evidente.

\section{A MODO DE CONCLUSIÓN}

El tejido de saberes teóricos, académicos, disciplinares y populares forman parte de un entramado complejo y heterogéneo por medio del cual podemos aproximarnos al fanzine ilustrado, ya que este es generado dentro de un amplio marco de producción cultural en la Ciudad de México, lugar donde las vivencias y experiencias de los colectivos y productores tienen lugar. El fanzine deviene históricamente en contradicciones y funciona como instrumento de exploración creativa que gira en torno a problemáticas políticas, económicas y sociales que se viven en el país. Este fenómeno juega un importante rol como expresión libre y espontánea de sectores juveniles que oscilan entre lo marginal y lo institucional. Es a la vez objeto y espacio provocado y originado de expresión de intereses diversos, sin un lugar fijo en el ámbito comercial pero no necesariamente sin lugar en lo popular. Las imágenes que podemos encontrar en los fanzines son parte de constructos sociales importantes, a los que podemos aproximarnos y de los que podemos atestiguar la representación gráfica de ideas alternas, con la finalidad de reflexionar sobre diversas formas de producción estética, que generan y auto-gestionan un lugar en la cotidianidad urbana en forma de expresión cultural.

\section{REFERENCIAS}

Aceves Bernal, A. (2015). Zin generación. Autoedición en la Ciudad de México (2005-2015). Recuperado de https://www.facebook.com/groups/904594652927123/ 
Analco, A. (2011). Desde abajo iy a contracorriente! El fanzine y los imaginarios juveniles urbanos. México, D.F.: Instituto Nacional de Antropología e Historia.

Arriaga, E. y Estrada, I. (2015). Fanzinología mexicana 1985 - 2015.

México, D.F: Universidad Nacional Autónoma de México.

Atton, C. (2002). Alternative media. London: Sage Publications. Pantoja, J. (2007). Cuando el Chopo despertó, el dinosaurio ya no estaba aní. De cómo nació la idea del Tianguis Cultural del Chopo. México: Universidad Autónoma de la Ciudad de México.

Ramírez, J. A. (1996). La contracultura en México. México:

Debolsillo.

\section{ACERCA DEL AUTOR}

Juan Alberto Martín del Campo Jiménez (juansatirigrafico@gmail.com) es maestro en Imagen, Arte, Cultura y Sociedad por la Universidad Autónoma del Estado de Morelos y licenciado en Diseño Gráfico por la Universidad Autónoma de Aguascalientes, ilustrador, investigador y docente en espacios institucionales e independientes (ORCID 0000-0001-7584-6834).

Recibido: 20/10/2018

Aceptado: 22/03/2019 
CÓMO CITAR ESTE ARTÍCULO

Martín del Campo Jiménez, J. A. (2020). El fanzine como fenómeno cultural en la Ciudad de México. Caleidoscopio Revista Semestral de Ciencias Sociales y Humanidades, 23(42), 107124. doi: $10.33064 / 42$ crscsh2154 